\title{
Radiation-induced acute injury of intensity-modulated radiotherapy versus three-dimensional conformal radiotherapy in induction chemotherapy followed by concurrent chemoradiotherapy for nasopharyngeal carcinoma: a prospective cohort study
}

\author{
Zexin Yao \\ Xiaoxuan Lei \\ General Hospital of Southern Theatre Command of PLA

\section{Zhiyan Chen} \\ Guangdong Pharmaceutical University

\section{Mengru Pang} \\ General Hospital of Southern Theatre Command of PLA \\ Jialin Huang \\ Guangdong Pharmaceutical University \\ Biao Cheng ( $\nabla$ chengbiaocheng@163.com ) \\ https://orcid.org/0000-0003-3383-1671
}

Guangdong Pharmaceutical University https://orcid.org/0000-0002-5655-5545

\section{Research}

Keywords: Nasopharyngeal carcinoma, Radiation-induced acute injury, Induction chemotherapy, IMRT, 3D-CRT

Posted Date: March 24th, 2020

DOI: https://doi.org/10.21203/rs.3.rs-18506/v1

License: (9) (i) This work is licensed under a Creative Commons Attribution 4.0 International License. Read Full License 


\section{Abstract}

Background: Induction chemotherapy (IC) combined with concurrent chemoradiotherapy (CCRT) was the new standard treatment for nasopharyngeal carcinoma (NPC). We aimed to address whether the addition of intensity-modulated radiotherapy (IMRT) compared to three-dimensional conformal radiotherapy (3D-CRT) aggravate radiation-induced acute injury of these patients.

Methods: We conducted a prospective study of consecutive patients with biopsy-proven nonmetastatic NPC who newly underwent radiotherapy and sequentially received IC, followed by CCRT at our institution. Among the 224 patients included, 108 (48.21\%) were treated with IMRT and $116(51.78 \%)$ with 3D-CRT. Clinicians evaluated routinely acute injury each day during radiotherapy according to the Radiation Therapy Oncology Group (RTOG). Radiation-induced dermatitis, oral mucositis, bone marrow toxicity and gastrointestinal toxicity were compared using the Kaplan-Meier method and the Log-rank test. Overall survival (OS), locoregional progression-free survival (LRFS) distant metastasis-free survival (DMFS) and progression-free survival (PFS) were analyzed during standard follow-up consultations.

Results: There was no difference in patient characteristics between groups; however, IMRT plans had higher docetaxel and nedaplatin compared with 3D-CRT plans. The most severe acute toxicities included oral mucositis in $96.43 \%$ and dermatitis in $88.84 \%$. Subset analysis revealed that Grade $3-4$ acute dermatitis, oral mucositis and bone marrow toxicity were not significantly lower in the IMRT than 3D-CRT ( $P>0.05)$. Patients in IMRT group achieved significantly lower risk of bone marrow toxicity (Hazard ratio $[\mathrm{HR}]=2.557, \mathrm{P}=0.0029$ ) in Kaplan-Meier test, but higher risk of leukopenia $(H R=0.492, P=0.0165)$ and gastrointestinal injury $(H R=0.432$, $\mathrm{P}=0.0011$ ). Multivariate analyses also demonstrated that IMRT, male gender and hepatitis were the independent prognostic factor for bone marrow toxicity ( $\mathrm{HR}=2.557, \mathrm{P}=0.0032)$. No significant difference was found between the 3D-CRT and IMRT groups in terms of survival. The use of IMRT was a predictive factor of significantly better short-term efficacy, whereas anemia was a significant independent predictor.

Conclusions: In a combined regimen of IC followed by CCRT for the treatment of NPC, IMRT seems to be an aggressive technique with a trend towards increased gastrointestinal and hematological toxicities than those treated with 3D-CRT. Predicting the occurrence time of various side effects is beneficial to early protection and focus on to coherent treatment.

\section{Background}

Nasopharyngeal carcinoma (NPC) is a special cancer of head and neck, with a high incidence (15 to 50 cases per 100,000 persons annually) and main causes of cancer death (50,000 persons per year) in endemic regions such as Southern China, Southern Asia, the Middle East, Northern Africa, Singapore, and Malaysia [1]. Radiotherapy (RT) is used in the primary treatment for NPC because of its inherent anatomic site and high radiosensitivity [2]. The currently recommended standard regimen is the addition of concurrent chemotherapy (CCRT) for NPC patients who receive RT with or without adjuvant chemotherapy being superior to radiotherapy alone [3]. Nevertheless, induction chemotherapy (IC) combined with the established CCRT regimen has attracted attention for the management of advanced NPC during recent decades [4]. The use of IC followed by definitive CCRT was associated with improved clinical outcomes, which could decrease distant metastases. IC consistently results in higher response and exerts a pronounced effect on distant metastases. However, the 
treatment inevitably carries higher rates of acute toxicities and late complications to normal tissues, including dermatitis, oral mucositis, bone marrow and gastrointestinal toxicity with a significant impact on the quality of life, unplanned treatment interruptions and leading to the development of tumors [5]. It is a great challenge to provide accurate radiative dose with minimal irradiation adverse events [6, 7].

More recently, the selectivity of radiation techniques has improved tremendously first by the replacement of two-dimensional (2D) planning by three-dimensional conformal radiotherapy (3D-CRT) techniques with a low rate of acute treatment toxicities and excellent rates of short-term local control. Besides, intensity-modulated radiation therapy (IMRT) is an advanced form of radiation technique allowing a more target coverage and dose homogeneity that delivers higher dose to the tumor and conforms to the scattering irradiation volume to critical organs while keeping less toxicity to skin and surrounding tissues [8,9]. Multiple dosimetry studies have demonstrated that IMRT has a similar survival and low risk on the occurrence of acute adverse events over 3DCRT in the management of breast, head and neck cancer $[10,11]$. To the best of our knowledge, more studies mainly focused on the local control and survival of tumors, but few compared 3D-CRT with IMRT for acute skin reaction and other side effects of NPC irradiation with a combined strategy of IC-CCRT [12]. However, data to comprehensive IMRT with IC-CCRT in the control arm was limited, the IMRT has not been shown to be superior to 3D-CRT.

Therefore, a prospective cohort study with the Kaplan-Meier method and the Log-rank analysis was performed to compare IMRT with 3D-CRT combined induction with concurrent chemotherapy for evaluating radiationinduced toxicities in a large patient collective on NPC. The order of occurrence for radiation-induced acute injuries is brought forward which is also one of creation in research perspective. In this paper, we reported the treatment outcome.

\section{Materials And Methods}

\section{Design}

We conducted a prospective cohort study in the department of oncology, General Hospital of Southern Theater Command in Guangzhou, China, from January 2016 to December 2018. Those with primary

histopathologically confirmed NPC treated in the department of oncology were enrolled. Inclusion criteria were aged $\geq 18$ years with a completion of radical radiotherapy and patients with weekly on-treatment visit documentation of acute treatment related toxicities. Patients with unresectable NPC of squamous cell carcinoma treated with induction chemotherapy prior to concurrent chemoradiation were included in the present analysis. A patient would be excluded if he or she had: (a) a history of radiotherapy to the head or neck; (b) Karnofsky performance score (KPS)<70; (c) severe heart, lung, liver or kidney dysfunctions unsuitable for radiotherapy; (d) transfer to other hospitals for treatment of irradiation. The medical follow-up included medical history with physical examination, adverse events, hematologic and chemical tests, panendoscopy with biopsies and radiologic evaluation. A patient's stage was determined based on the Union for International Cancer Control/American Joint Cancer Committee (UICC/AJCC) TNM classification. Tumor histology was classified according to the World Health Organization classification. 


\section{Radiotherapy}

The planning CT dataset was acquired using a 16-detector scanner. All patients underwent RT with 6 to $10 \mathrm{MV}$ photon linear accelerators using either 3D-CRT or IMRT. Helical TomoTherapy combines a rotational IMRT with a translational movement of the couch. CT image data were reconstructed as 5-mm sections for 3D-CRT and 2$\mathrm{mm}$ sections for IMRT. The treatment using radiotherapy technologies and fractionated dose with an individually optimized plan for each patient was considered mainly according to the wishes of the patients. The gross tumor volume (GTV) was defined by the International Commission on Radiation Units and Measurements Reports 50 and 62, including gross primary tumors (GTVnx) and involved lymph nodes (GTVnd) determined from clinical and imaging examinations. The clinical margin volume (CTV) for high-risk (CTV1) should include the entire nasopharynx, retropharyngeal lymph nodal regions and any high-risk nodal regions. The CTV for low-risk (CTV2) was recognized as the next station of the positive lymph nodes and the elective neck area. The GTVnx plus a $3 \mathrm{~mm}$ margin was defined as planning gross tumor volume (PGTVnx) with 60-70 Gy and the GTVnd plus a $5 \mathrm{~mm}$ margin was defined as PGTVnd with 60-70 Gy. Other two planning target volumes (PTV1 and PTV2) were defined as CTV1 plus a $3 \mathrm{~mm}$ margin with 60Gy and CTV2 plus a $3 \mathrm{~mm}$ margin with 54Gy. Both patient groups were treated with one fraction of 1.97-2.33Gy daily, five times per week. Booster doses were not included in color assessment for this analysis.

\section{Chemotherapy}

All patients were received one to four cycles of platinum-based IC before radiotherapy for NPC and one to three cycles CCRT with platinum-based treatment $\left(40 \mathrm{mg} / \mathrm{m}^{2}\right)$ for 3 days. The most common induction regimens included TPF (Taxol $210 \mathrm{mg} / \mathrm{m}^{2} /$ day on day 1 , platinum $40 \mathrm{mg} / \mathrm{m}^{2} /$ day on days $1-3$, and 5-fluorouracil [5-FU] $750 \mathrm{mg} / \mathrm{m}^{2} /$ day on days $1-3$ ), DPF (docetaxel $120 \mathrm{mg} / \mathrm{m}^{2} /$ day on day 1 , platinum $40 \mathrm{mg} / \mathrm{m}^{2} /$ day on days $1-$ 3 , and $5-\mathrm{FU} 750 \mathrm{mg} / \mathrm{m}^{2} /$ day on days $1-3$ ), DP (docetaxel $120 \mathrm{mg} / \mathrm{m}^{2} /$ day on day 1 , platinum $40 \mathrm{mg} / \mathrm{m}^{2} /$ day on days $1-3)$, TP (Taxol $210 \mathrm{mg} / \mathrm{m}^{2} /$ day on day 1 , platinum $40 \mathrm{mg} / \mathrm{m}^{2} /$ day on days $\left.1-3\right)$. The treatment plan was administered at the discretion of the treating physicians.

\section{Follow up and toxicity evaluation}

All the subjects underwent weekly examinations for acute toxicities and treatment response during radiation therapy. The evaluated radiation-induced injuries including oral mucositis, skin injury, dermatitis, Hyperpigmentation, bone marrow toxicity, leukopenia, vomiting and gastrointestinal toxicity. They were recorded the date prospectively when it first appeared and scored according to the Radiation Therapy Oncology Group (RTOG). The index date was the start date for RT and the date of toxicity evaluation in the cohort. If a patient experienced RTOG grade 4 toxic effects or was hospitalized, treatment was either delayed or suspended. The primary endpoint was development of RTOG grade with radiation-induced acute injuries. Patients were followed up every 3 months for 2 years after treatment.

\section{Treatment effect}


The short-term curative effects of the two groups of patients were evaluated three months after radiotherapy. The local control rate of treatment includes rate of complete remission (CR) and partial relief (PR). Secondary outcomes of this study included overall survival (OS, calculated as the time from start of treatment until death from any cause), locoregional relapse-free survival (LRFS, defined as the time from start of treatment until recurrence in the nasopharyngeal or neck area), distant metastasis-free survival (DMFS, defined as the time from start of treatment until detection of distant metastasis) and progression-free survival (PFS, defined as the time from start of treatment until disease progression). Each follow-up included physical examinations, nasoendoscopy, chest imaging, ultrasound of abdomen, MRI scan of the nasopharynx and bone scan. Additional examinations were performed when it is indicated to confirm local recurrence or distant metastasis by an experienced doctor. Patients without the information on disease progression or lost to follow-up were treated as censored data.

\section{Statistical Analysis}

Patterns of time-to-event were analyzed: the incidence of periods and the median days of occurred acute toxicities after IMRT or 3D-CRT were calculated using the Life-Table and Kaplan-Meier methods, compared with the Log-rank test. Baseline characteristics including age, gender, cigarette smoking, alcohol consumption, AJCC clinical stage, comorbidity, lymphatic metastasis, irradiation fraction dose and KPS, BMl, follow-up periods and course of cancer were compared in IMRT and 3D-CRT groups using Chi-square ( $\chi 2)$ test, Fisher's exact test, twotailed Student's t-test or Wilcoxon Rank-sum test where appropriate. Multivariate Logistic Regression and Cox Proportional Hazard models were performed to calculate the hazard ratio (HR) for determining whether radiotherapy related factors were significant independent predictors. The Kaplan-Meier method was used to estimate OS, LRFS, PFS, DMFS. A $p$-value of $<0.05$ from two-sided tests was defined as being of statistically significant. All statistical analyses were performed with the SAS 9.4 statistical software (SAS Institute Inc. USA, https://www.sas.com).

\section{Results}

\section{Patients and treatments characteristics}

The consolidated standards of reporting trials (CONSORT) flow-chart for the study is depicted in Fig. 1. The median follow-up time was 15 months (range 1-46 months) for the entire cohort of patients. Table 1 summarizes the baseline data and treatment characteristics of 224 patients for the IMRT and 3D-CRT groups included in the trial. A total of 108 patients (mean age: $49.05 \pm 11.52$ years, range $23-76$ ) received IMRT and 106 (mean age: $51.22 \pm 11.26$ years, range $27-78)(P=0.1556)$ received conventional 3D-CRT. In both groups, there were more males than females with a male: female ratio of approximately 3.7:1. The most patients presented with stage III (37.95\%) and stage IV (42.41\%) disease. There were $62.04 \%$ patients with T3-4 in IMRT group and $50.86 \%$ in 3D-CRT group $(P=0.2363), 60.18 \%$ vs. $67.24 \%$ with $\mathrm{N} 2-3(P=0.4778)$, overall stage was balanced $(P=0.9907)$. The median radiotherapy dose was $68.68 \mathrm{~Gy}$ in both groups and the daily dose was always 219 cGy in the IMRT group and 202 cGy in the 3D-CRT group. Furthermore, docetaxel and nedaplatin of induction chemotherapy were applied in a higher fraction of individuals receiving IMRT (IMRT vs. 3D-CRT: $31.48 \%$ vs. $16.38 \%, P=0.0281 ; 17.59$ vs. $5.17 \%, P=0.0023$ ) and cisplatin of concurrent chemotherapy 
was used in a lower fraction of patients (IMRT: $43.52 \%$ vs. $56.03 \%$ with 3D-CRT, $P<0.0001$ ). There were no significant differences in age, gender, current smoker and drinker, tumor TNM stage, comorbidities, process of cancer, BMI, total radiation dosage, 5-fluorouracil treatment, length of RT to CC and IC to RT. In multiple Logistic regression analysis, there is no bearing with the choices of two radiotherapy technologies. Overall, these characteristics were largely representative of nasopharyngeal cancer population in the community, ensuring good external validity with widespread applicability and generalization of results.

\section{Acute side effects of treatment}

Relevant side effects were reported by most patients. Acute complications are reported in Table 2. At the end of follow-up, almost all patients described at least some kind of radiation-induced injuries (99.07\% in the 3D-CRT and $96.55 \%$ in the IMRT group, $P=0.2016)$. Acute dermatitis was observed $89.81 \%$ of patients in the IMRT and $87.93 \%$ in the 3D-CRT group $(P=0.6546)$. Oral mucositis occurred $96.30 \%$ and $96.55 \%$ of patients in the IMRT and 3D-CRT groups, respectively $(P=0.9180)$. Bone marrow toxicity was present $25.93 \%$ of patients treated in the IMRT group and $51.72 \%$ in the 3D-CRT group $(P<0.0001)$. There was a significantly better control of hyperpigmentation, bone marrow toxicity and otitis media in IMRT, but a trend toward better moist desquamation, erythema, xerostomia and gastrointestinal injury in patients treated with 3D-CRT remains $(P<0.05)$. Dermatitis, exudate, oral mucositis, anemia, leukopenia and so on were no differently observed at IMRT and 3D-CRT. The proportions of patients with physician-rated RTOG grade 3 or worse acute dermatitis, oral mucositis and bone marrow toxicity were $39.29 \%, 56.59 \%$ and $51.85 \%$. Severe acute dermatitis, oral mucositis and bone marrow toxicity were not significantly lower in the IMRT arm as compared to 3D-CRT.

Fig. 2 show the radiation-induced toxicity curves for patients receiving IMRT vs. 3D-CRT regimens of radiotherapy. The earliest occurrence of radiation-induced was oral mucositis (Table 3). Median times to occur oral mucositis was 12 days in IMRT group and 13 days in 3D-CRT group. Next, acute dermatitis was 27 days in IMRT group and 29 days in 3D-CRT group. For the whole study population, 2-weeks morbidity for dermatitis, oral mucositis, bone marrow and gastrointestinal toxicities were $25.00 \%, 66.67 \%, 6.48 \%, 22.22 \%$ in IMRT group and $9.76 \%, 56.53 \%, 14.41 \%, 9.86 \%$ in 3D-CRT group, respectively. The 4-weeks incidence were $53.70 \%$ vs. $49.07 \%, 92.59 \%$ vs. $86.69 \%, 13.89 \%$ vs. $26.25 \%$ and $26.85 \%$ vs. $10.77 \%$, respectively. Comparison of toxicities demonstrated that IMRT was associated with lower bone marrow toxicity than 3D-CRT $(P=0.0029)$, but higher gastrointestinal injury and leukopenia with IMRT (gastrointestinal: $P=0.0011$, leukopenia: $P=0.0165$ ). There were no significant differences in other acute toxicities between 3D-CRT and IMRT in univariate survival analysis.

\section{Predictive factors}

In a Cox proportional hazards analysis, 3D-CRT was significantly associated with the bone marrow toxicity in our survival analysis (Hazard ratio $[\mathrm{HR}]=2.557, P=0.0032$ ) (Table 4). And IMRT was significantly related to gastrointestinal toxicity $(H R=0.432, P=0.0228)$ and leukopenia $(H R=0.492, P=0.0151)$. Only male gender (HR $=2.640, P=0.0046)$ and hepatitis $(H R=3.629, P=0.0002)$ were significantly associated with an unfavorable bone marrow toxicity. If the analysis was restricted to gastrointestinal injury, docetaxel, cisplatin and 5-FU of IC and nedaplatin of CC drugs were detected as the additional predictors. The technologies of 
radiotherapy could be an independent factor of leukopenia $(H R=0.492, P=0.0151)$. It was demonstrated that oral mucositis was not associated with IMRT, which related to older adults, hepatitis and 5-FU of CC.

\section{Outcome and efficacy of treatment}

For treatment outcome, Fig. 3 shows the survival curves that there were no differences in mortality, recurrencefree and distant metastasis and progression-free at 2 years after treatment in patients treated with IMRT and 3D-CRT. The 2-year Kaplan-Meier estimates of OS, LRFS, DMFS and PFS were 100\% vs. 100\% $(P=1.0000)$, $100.00 \%$ vs. $94.82 \%$ ( $P=0.5018), 66.05 \%$ vs. $81.00 \%(P=0.0519)$ and $89.80 \%$ vs. $87.64 \%(P=0.3446)$ for the IMRT and 3D-CRT arms respectively. At 3 months after the end of treatment, $10.19 \%$ vs. $6.90 \%$ of patients treated with IMRT and 3D-CRT had reported a CR, PR rates were higher in patients receiving IMRT compared to patients with 3D-CRT (55.56\% vs. 30.17\%, $P=0.0007)$. In multivariate regression analysis, the outcome and efficacy of treatment were not significantly associated with two groups. There was a risk factor of anemia for short-term efficacy (HR = 3.681, 95\%Cl: 1.117-12.129).

\section{Discussion}

The superiority of IC-CCRT combined with radiation in patients was first demonstrated in the landmark which replaced chemoradiotherapy alone with induction platinum-based chemotherapy followed by concurrent high dose cisplatin with radiotherapy [13]. The scheme of induction therapy can effectively alleviate the lesions and create improved radiotherapy conditions for locoregionally advanced NPC, especially in patients with giant lesions, achieving better survival and prognosis [3]. However, one of the outcomes of induction chemotherapy can increase radiation-induced toxicities and adverse events, such as dermatitis or oral mucositis $[8,14,15]$. There is currently no well-defined standard of care in the management of patients with radiation-induced acute injuries. Radiation-related injury, which frequently occurred in patients treated with NPC, could cause physical and mental suffering due to pain, ulcer, exudate, various cosmetic problem and reduced quality of life [16, 17]. To reduce acute toxicity, a better focusing of radiation were actively studied and avoiding the integument. IMRT and 3D-CRT have been demonstrated an improved treatment outcome and lower skin toxicity in other head and neck cancer, they are the primary radiotherapy techniques for cancer patients during recent decades [18]. However, the prevalence of radiation-related complication with induction chemoradiotherapy in the current literature varies widely [19-21]. There is still a lack of evidence and controversy comparing IMRT with 3D-CRT for NPC. To the best of our knowledge, there is no randomized controlled comparison for IMRT vs. 3D-CRT in NPC treated with IC-CCRT bringing about acute toxicity. For this reason, we should pay attention to injurysparing IMRT and 3D-CRT, which is an active method to reduce radiation-related acute toxicity. The investigation of the occurred timing for acute adverse events will be benefit to prevent these radiation-related toxicities during the treatment [22]. The purpose of this study was to provide a comprehensive description of radiation-induced toxicity rates and acute side effects for IMRT vs. 3D-CRT in NPC with platinum-based ICCCRT.

Notably, the present study is the first to prospectively measure and report the occurred time of acute toxicity after initiation of radiation treatment and comparison for two irradiation techniques within the analysis of a Cox proportional hazards model. That provided a new method for further study between radiation injury and 
radiotherapy in cancer patients after then. Our novel finding of a differential effect between the toxic risk of 23 weeks and the proportion of acute injury on the treatment compared with 3D-CRT that IMRT may confer a substantive disadvantage to patients been put off treatment plan for bringing forward adverse events. A Cox proportional hazards model of this study stated less bone marrow toxicity and worse gastrointestinal control, a trend toward earlier occurred white blood cell toxicity in patients treated with IMRT.

Acute skin toxicity in the form of radiation dermatitis or skin hyperpigmentation is a common problem experienced by patients undergoing NPC irradiation. The most common acute adverse events were oral mucositis and dermatitis, which occurred in $96.43 \%$ and $88.84 \%$ of the patients, the earliest occurrence of oral mucositis was observed during the treatment. A possible explanation for these results may come from susceptible to external infection and close-range irradiation. A phase III randomized trial of IC-CCRT in patients with locally advanced head and neck cancer stated that the most common toxicities were mucositis and dermatitis [23]. In our study, the incidence rate of these adverse events was not in contradiction to previous reports. Levy et al. [24] also reported that the highest morbidity of acute toxicity was dermatitis (97\%) with concurrent radiotherapy and cetuximab after taxane-based induction chemotherapy in locally advanced head and neck cancer. Concurrent chemotherapy in NPC treated with neoadjuvant chemotherapy followed by IMRT was exhibited $48.3 \%$ dermatitis, $49.2 \%$ oral mucositis, $38.1 \%$ bone marrow toxicity, $40.9 \%$ xerostomia and $21.2 \%$ nausea vomiting [25]. There are more than $40 \%$ of patients occurred severity acute injuries for most of locoregional advanced cancer during treatment in previous studies. The investigation of IMRT dose distribution to the skin in head and neck squamous cell carcinoma was reported the incidence of grade 3 and 4 radiation dermatitis was $41.1 \%$ in patients included and $50 \%$ vs $36.6 \%$ in the cetuximab and cisplatin cohorts, respectively [26]. Grade 3-4 hematologic toxicities and radiotherapy-related oral mucositis during the period of locoregionally advanced nasopharyngeal carcinoma treated with nimotuzumab plus IMRT with chemotherapy were reported in $7.4 \%$ and $10.9 \%$ patients, and there were only $8.6 \%$ patients who complained of serious xerostomia [27]. The patients experienced severity toxic effects or cannot tolerate it during irradiation, which would either delay or suspend treatment. Nevertheless, it appears that wide rate of radiation-induced acute injuries may speculate on radiation technique, chemotherapy scheduling and the location of tumor.

Several studies have revealed that IMRT could provide reduced irradiation to the normal tissue without compromising target volume coverage, which is an advantage of the technique [28]. Data directly comparing acute side effects of NPC patients treated with IMRT and 3D-CRT are lacking in the literature as well, but lower rates of wound healing complications with IMRT were referred to more recent studies [18]. In our study, reduced hyperpigmentation and bone marrow toxicity appeared more remarkable in light of the treatment performed in the IMRT group than those of the 3D-CRT group and this difference remained robust in a univariate and multivariate analysis. As E. Hardee et al. [29] demonstrated that IMRT moderately decreased rates of subacute hyperpigmentation for hypofractionated whole-breast radiotherapy at 1 month of follow-up. Under this, IMRT had possessed a more homogenous dose distribution, which was reported as a good alternative to treat cervix carcinoma with bone marrow toxicity [30]. The clinical trial was demonstrated that the cause of thrombocytopenia in patients with chronic hepatitis $\mathrm{C}$ virus (HCV) infection, which was possibly caused by improvement of hypersplenism and HCV-induced bone marrow toxicity resulting from anti-HCV therapy [31]. Acute dermatitis and oral mucositis of the two groups were not obvious different in our study. This may have been because of strictly controlled other variables between radiation techniques. Ghosh-Laskar et al. [32] also showed that there were no significant differences in the incidence of some acute toxicities between IMRT and 
3D-CRT, such as mucositis, dermatitis and dysphagia, which is in good accordance with our findings. Borm et al. [10] released that 3D-CRT allows a homogeneous dose distribution with similar skin toxicity as compared to studies performing IMRT with chemotherapy. Furthermore, a Cox proportional hazards model suggested that oral mucositis and dermatitis are truly driven by the selected IC 5-FU treated scheme or others. This can be attributed to the fact that the extra regimens of IC-CCRT may have weakened the protective effect of IMRT on the skin. However, there are some findings of previously reported studies different from above results. Liang et al. [33] concluded that dose homogeneity across nasopharyngeal in the IMRT plan can reduce the adverse effects related to the acute skin toxicity of patients according to the RTOG toxicity criteria. Katano et al. [34] analyzed various radiation-related factors in terms of cosmetic outcome and found that the radiation techniques and doses delivered to the nasopharynx were statistically significant factors. Comparing with 3DCRT, patients treated with IMRT for anal carcinoma had a significantly lower degree of skin toxicity and higher rate of acute diarrhea, but rates of hematological toxicity and proctitis were not reduced [18]. Comparison of toxicities demonstrated that IMRT was a safe regimen with less xerostomia, acute dermatitis and favorable locoregional control, survival rates during treatment of locally advanced oropharyngeal carcinoma [35]. Since acute side affections frequently limit radiation treatment, IMRT might have enabled more aggressive treatment in some patients.

However, not all side effects of radiotherapy were superior in the IMRT group. We noted a significantly increased rate of gastrointestinal injury and leukopenia upon IMRT, observed in univariate and multivariate analyses, which is not entirely clear. One possible explanation could be a different distribution of radiation in the small intestine. This difference with higher treatment rates and dosages for 5-FU and docetaxel drugs in the IMRT group, might to some extent explain the increase in acute diarrhea in the IMRT group. There was a study also reported a trend toward more GI toxicity in IMRT [18]. In addition, our study also demonstrated a trend toward higher hematological toxicity in the IMRT group. In contrast to that, lower hematological toxicity for IMRT compared to 3D-CRT for the treatment of cervical cancer was demonstrated in some studies. Strikingly, our multivariable analysis found that the negative impact of IMRT to leukopenia was comparable, which greater than the effect of these chemotherapy drugs on these toxicities. This finding is different from the result of Chi-square test and fully shows the superiority of Log-rank method. As shown in a simulation by Kuma et al. [30], a cohort of cervical cancer patients receiving definitive chemoradiation was assessed that more frequent severity leukopenia was found in the IMRT group. As induction and concurrent chemotherapy are the major part of the treatment, which cannot be ignored, the suggestion of this study is to minimize un-necessary irradiation dosage to decrease hematological toxicity.

Our data suggest better local tumor control upon IMRT treatment. Apparently, IMRT allows a more localized focus of radiation in the primary tumor area which might have received more radiation volume and more homogenous radiation over its entire volume for maximum oncological effects. However, previously reported studies with NPC have suggested that IMRT gives at least the same outcome in primary tumor as threedimensional conformal techniques [21]. In addition, highly similar survival outcomes for IMRT and 3D-CRT had reported in most studies as our study showed. Yan et al. [36] concludes that IMRT and 3D-CRT have almost the same short-term and long-term clinical effects in the treatment combined with postoperative chemotherapy of nasopharyngeal carcinoma and both of them have high effectiveness and safety. No survival benefits had been observed while comparing IMRT versus 3D-CRT in cervical esophageal squamous cell carcinoma patients treated by concurrent chemoradiotherapy [37]. A National Cancer Database Analysis reports that there was no 
difference in OS for patients who received IMRT versus 3D-CRT, IMRT was associated with similar survival as 3D-CRT [38]. Another meta-analysis showed that the 3-year OS, DFS rates had no significant difference between the IMRT and 3D-CRT groups for gastric cancer, but IMRT might be superior to 3D-CRT in treating patients with gastric cancer in terms of local control rates [21]. But beyond that, there are also studies of IMRT patients had better tumor control than 3D-CRT with equal or better oncological results for anal carcinoma patients [18]. A meta-analysis provided the results that IC-CRT should be the most suitable regimen for locoregionally advanced NPC in the IMRT era [39]. Improvement of survival in our study upon IC-CCRT treatment is encouraging.

Some limitations must be considered for this study. Taking a full account of the occurrence of radiationinduced acute injury is valuable. However, the grade 3 or worse of dermatitis or oral mucositis had been not investigated their deterioration time during the treatment. The severity acute injuries may better report the impact of side effects between IMRT and 3D-CRT on the treatment of patients. Nevertheless, our data provide a real-world experience on adjuvant therapy except IMRT or 3D-CRT might change outcome and side effects in radiochemotherapy for NPC. Acute toxicity should be analyzed with caution as the follow-up of patients treated by IMRT is lower than that of 3D-RCT group. However, no difference in survival was noted between the groups. The number of tumor relapses significantly different may be explained by the difference of follow-up between the groups.

\section{Conclusion}

In summary, our data show that IMRT can reduce local side effects of IC-CCRT scheme such as hyperpigmentation and bone marrow toxicity, but increase moist desquamation, xerostomia, gastrointestinal and hematological toxicity, enable a more aggressive radiochemotherapy. We found better tumor control rates with IMRT after the end of treatment, suggesting significant oncological benefits over 3D-CRT. The effects of acute toxicities such as anemia may lead to lower tolerance for tumor treatment, which was a factor that compromises good results. In the era of IC-CCRT, the treatment of IMRT and 3D-CRT should give sufficient consideration to the occurrence of acute injuries and take active preventive measures in time. In a combined regimen of IC followed by CCRT for the treatment of NPC, predicting the occurrence time of various side effects is beneficial to early protection and focus on coherent treatment.

\section{Abbreviations}

NPC: Nasopharyngeal carcinoma; RT: Radiotherapy; IC: Induction chemotherapy; CCRT: Concurrent chemoradiotherapy; IC-CCRT: Induction chemotherapy followed by concurrent chemoradiotherapy; 2D: Twodimensional; 3D-CRT: Three-dimensional conformal radiotherapy; IMRT: Intensity modulated radiation therapy; KPS: Karnofsky performance score; UICC/AJCC: Union for International Cancer Control/American Joint Cancer Committee; GTV: gross tumor volume; CTV: Clinical target volume; PTV: Planning target volume; 5-FU: 5fluorouracil; RTOG: Radiation Therapy Oncology Group; CR: complete remission; PR: partial relief; OS: Overall survival; LRFS: Locoregional progression-free survival; DMFS: Distant metastasis-free survival; PFS:

Progression-free survival; HR: the hazard ratio; CONSORT: The consolidated standards of reporting trials; HCV: Hepatitis $\mathrm{C}$ virus 


\section{Declarations}

\section{Ethics approval and consent to participate}

Due to the data sources based on a health record database of Electronic Medical Record (EMR), this study did not need require ethics committee approval according to Institutional Review Board of General Hospital of Southern Theater Command. The entire study followed the ethical principles of the Declaration of Helsinki. This study was approved by our institution. The consent for publication was obtained from every patient.

\section{Consent for publication}

Not applicable.

\section{Availability of data and materials}

The data supporting the conclusions of this article are included within the article.

\section{Competing interests}

The authors declare that they have no competing interests.

\section{Funding}

This study was supported by a grant of the National Natural Science Foundation of China (81272105, and 81671924), the National Key Research and Development Plan of China (2017YFC1103301), the Science and Technology Key Project of Guangdong Province (2014B020212010), the Science and Technology Planning Project of Guangdong Province of China (2015B020233012), and the Military Medical Innovation Special Projects (18CXZ029).

\section{Authors' contributions}

ZY designed the study. XL and MP performed contouring, treatment planning and the statistical analysis. JH and $\mathrm{ZC}$ reviewed the data. All authors discussed the data. $\mathrm{ZY}$ and $\mathrm{BC}$ drafted the manuscript. All co-authors read and approved the manuscript.

\section{Acknowledgements}

Not applicable.

\section{Author details}


${ }^{1}$ Department of Public Health, Guangdong Pharmaceutical University, Guangzhou 510310, China. ${ }^{2}$ Department of Burn and Plastic Surgery, General Hospital of Southern Theater Command of PLA, Guangzhou 510010, China. ${ }^{3}$ Department of Oral and Maxillofacial Surgery/Pathology, Amsterdam UMC and Academic Center for Dentistry Amsterdam (ACTA), Vrije Universiteit Amsterdam, Amsterdam Movement Science, Amsterdam, The Netherlands.

\section{References}

1.Fangzheng W, Chuner J, Haiyan Q, Quanquan S, Zhimin Y, Tongxin L, et al. Survival without concurrent chemotherapy for locoregionally advanced nasopharyngeal carcinoma treated with induction chemotherapy plus intensity-modulated radiotherapy: Single-center experience from an endemic area. Medicine. 2019;98(51):e18484.

2.Beddok A, Feuvret L, Noel G, Bolle S, Deberne M, Mammar H, et al. Efficacy and toxicity of proton with photon radiation for locally advanced nasopharyngeal carcinoma. Acta Oncol. 2019;58(4):472-4.

3.Yang Q, Zhao TT, Qiang MY, Hu L, Lv X, Ye YF, et al. Concurrent Chemoradiotherapy versus Intensitymodulated Radiotherapy Alone for Elderly Nasopharyngeal Carcinoma Patients with Pre-treatment Epstein-Barr Virus DNA: A Cohort Study in an Endemic Area with Long-term Follow-up. J Cancer. 2018;9(17):3023-31.

4.Liu SL, Sun XS, Xie HJ, Chen QY, Lin HX, Liang H, et al. Comparing three induction chemotherapy regimens for patients with locoregionally advanced nasopharyngeal carcinoma based on TNM stage and plasma Epstein-Barr virus DNA level. BMC cancer. 2020;20(1):89.

5.Fuzissaki MA, Paiva CE, Oliveira MA, Lajolo Canto PP, Paiva Maia YC. The Impact of Radiodermatitis on Breast Cancer Patients' Quality of Life During Radiotherapy: A Prospective Cohort Study. J Pain Symptom Manage. 2019;58(1):92-9.e1.

6.Ho AY, Olm-Shipman M, Zhang Z, Siu CT, Wilgucki M, Phung A, et al. A Randomized Trial of Mometasone Furoate $0.1 \%$ to Reduce High-Grade Acute Radiation Dermatitis in Breast Cancer Patients Receiving Postmastectomy Radiation. International journal of radiation oncology, biology, physics. 2018;101(2):325-33.

7.Chen H, Wu M, Li G, Hua L, Chen S, Huang H. Association between XRCC1 single-nucleotide polymorphism and acute radiation reaction in patients with nasopharyngeal carcinoma: A cohort study. Medicine (Baltimore). 2017;96(44):e8202.

8.Kuang WL, Zhou Q, Shen LF. Outcomes and prognostic factors of conformal radiotherapy versus intensitymodulated radiotherapy for nasopharyngeal carcinoma. Clin Transl Oncol. 2012;14(10):783-90.

9.Zhang L, Shan GP, Li P, Cheng PJ. The role of concurrent chemotherapy to intensity-modulated radiotherapy (IMRT) after neoadjuvant docetaxel and cisplatin treatment in locoregionally advanced nasopharyngeal carcinoma. Med Oncol. 2015;32(3):41.

10.Borm KJ, Loos M, Oechsner M, Mayinger MC, Paepke D, Kiechle MB, et al. Acute radiodermatitis in modern adjuvant 3D conformal radiotherapy for breast cancer - the impact of dose distribution and patient related 
factors. Radiat Oncol. 2018;13(1):218.

11.Moon SH, Cho KH, Lee CG, Keum KC, Kim YS, Wu HG, et al. IMRT vs. 2D-radiotherapy or 3D-conformal radiotherapy of nasopharyngeal carcinoma: Survival outcome in a Korean multi-institutional retrospective study (KROG 11-06). Strahlentherapie und Onkologie: Organ der Deutschen Rontgengesellschaft [et al]. 2016;192(6):377-85.

12.Chen JL, Huang YS, Kuo SH, Hong RL, Ko JY, Lou PJ, et al. Intensity-modulated radiation therapy achieves better local control compared to three-dimensional conformal radiation therapy for T4-stage nasopharyngeal carcinoma. Oncotarget. 2017;8(8):14068-77.

13.Frikha M, Auperin A, Tao Y, Elloumi F, Toumi N, Blanchard P, et al. A randomized trial of induction docetaxelcisplatin-5FU followed by concomitant cisplatin-RT versus concomitant cisplatin-RT in nasopharyngeal carcinoma (GORTEC 2006-02). Ann Oncol. 2018;29(3):731-6.

14.Kong L, Zhang YW, Hu CS, Guo Y. Neoadjuvant chemotherapy followed by concurrent chemoradiation for locally advanced nasopharyngeal carcinoma. Chinese journal of cancer. 2010;29(5):551-5.

15.Zhang J, Chen S, Li G, Zhang W, Qin T, Yin P, et al. Induction chemotherapy followed by concurrent chemoradiotherapy vs. concurrent chemoradiotherapy for locoregionally advanced nasopharyngeal carcinoma: a retrospective cohort study. Cancer Chemother Pharmacol. 2017;79(6):1087-97.

16.Li H, Li L, Huang X, Li Y, Zou T, Zhuo X, et al. Radiotherapy-induced dysphagia and its impact on quality of life in patients with nasopharyngeal carcinoma. Strahlentherapie und Onkologie: Organ der Deutschen Rontgengesellschaft [et al]. 2019;195(6):457-67.

17.McDowell LJ, Rock K, Xu W, Chan B, Waldron J, Lu L, et al. Long-Term Late Toxicity, Quality of Life, and Emotional Distress in Patients With Nasopharyngeal Carcinoma Treated With Intensity Modulated Radiation Therapy. International journal of radiation oncology, biology, physics. 2018;102(2):340-52.

18.Sauter M, Lombriser N, Butikofer S, Keilholz G, Kranzbuhler H, Heinrich H, et al. Improved treatment outcome and lower skin toxicity with intensity-modulated radiotherapy vs. 3D conventional radiotherapy in anal cancer. Strahlentherapie und Onkologie: Organ der Deutschen Rontgengesellschaft [et al]. 2020.

19.Ta MH, Schernberg A, Giraud P, Monnier L, Darai E, Bendifallah S, et al. Comparison of 3D conformal radiation therapy and intensity-modulated radiation therapy in patients with endometrial cancer: efficacy, safety and prognostic analysis. Acta oncologica (Stockholm, Sweden). 2019;58(8):1127-34.

20.Ito M, Kodaira T, Tachibana H, Tomita N, Makita C, Koide Y, et al. Clinical results of definitive chemoradiotherapy for cervical esophageal cancer: Comparison of failure pattern and toxicities between intensity-modulated radiotherapy and 3-dimensional conformal radiotherapy. Head \& neck. 2017;39(12):240615.

21.Ren F, Li S, Zhang Y, Zhao Z, Wang H, Cui Y, et al. Efficacy and safety of intensity-modulated radiation therapy versus three-dimensional conformal radiation treatment for patients with gastric cancer: a systematic review and meta-analysis. Radiation oncology (London, England). 2019;14(1):84. 
22.Blakaj A, Bonomi M, Gamez ME, Blakaj DM. Oral mucositis in head and neck cancer: Evidence-based management and review of clinical trial data. Oral oncology. 2019;95:29-34.

23.Cohen EE, Karrison TG, Kocherginsky M, Mueller J, Egan R, Huang CH, et al. Phase III randomized trial of induction chemotherapy in patients with N2 or N3 locally advanced head and neck cancer. J Clin Oncol. $2014 ; 32(25): 2735-43$.

24.Levy A, De Felice F, Bellefqih S, Guigay J, Deutsch E, Nguyen F, et al. Toxicity of concomitant cetuximab and radiotherapy with or without initial taxane-based induction chemotherapy in locally advanced head and neck cancer. Head \& neck. 2016;38 Suppl 1:E905-10.

25.Chang H, Peng L, Tao YL, Chen C, Xiao WW, Hu YH, et al. Necessity of concurrent chemotherapy in N2-3 nasopharyngeal carcinoma treated with neoadjuvant chemotherapy of $>$ / = 3 cycles followed by intensitymodulated radiotherapy. Cancer Med. 2019;8(6):2823-31.

26.Bonomo P, Talamonti C, Desideri I, Marrazzo L, Pezzulla D, Rampini A, et al. Analysis of skin dose distribution for the prediction of severe radiation dermatitis in head and neck squamous cell carcinoma patients treated with concurrent chemo-radiotherapy. Head \& neck. 2020;42(2):244-53.

27.Wang F, Jiang C, Ye Z, Liu T, Sun Q, Yan F, et al. Treatment Outcomes of 257 Patients with Locoregionally Advanced Nasopharyngeal Carcinoma Treated with Nimotuzumab Plus Intensity-Modulated Radiotherapy with or without Chemotherapy: A Single-Institution Experience. Transl Oncol. 2018;11(1):65-73.

28.Jo IY, Kim SW, Son SH. Dosimetric evaluation of the skin-sparing effects of 3-dimensional conformal radiotherapy and intensity-modulated radiotherapy for left breast cancer. Oncotarget. 2017;8(2):3059-63.

29. Hardee ME, Raza S, Becker SJ, Jozsef G, Lymberis SC, Hochman T, et al. Prone hypofractionated wholebreast radiotherapy without a boost to the tumor bed: comparable toxicity of IMRT versus a 3D conformal technique. Int J Radiat Oncol Biol Phys. 2012;82(3):e415-23.

30.Kumar T, Schernberg A, Busato F, Laurans M, Fumagalli I, Dumas I, et al. Correlation between pelvic bone marrow radiation dose and acute hematological toxicity in cervical cancer patients treated with concurrent chemoradiation. Cancer management and research. 2019;11:6285-97.

31.Ishizu Y, Ishigami M, Hayashi K, Honda T, Kuzuya T, Ito T, et al. Rapid increase of platelet counts during antiviral therapy in patients with hepatitis $C$ virus infection. Hepatology research: the official journal of the Japan Society of Hepatology. 2020;50(1):47-56.

32.Ghosh-Laskar S, Yathiraj PH, Dutta D, Rangarajan V, Purandare N, Gupta T, et al. Prospective randomized controlled trial to compare 3-dimensional conformal radiotherapy to intensity-modulated radiotherapy in head and neck squamous cell carcinoma: Long-term results. Head Neck. 2016;38 Suppl 1:E1481-7.

33.Liang SB, Wang Y, Hu XF, He SS, Yang XL, Liu LZ, et al. Survival and Toxicities of IMRT Based on the RTOG Protocols in Patients with Nasopharyngeal Carcinoma from the Endemic Regions of China. J Cancer.

2017;8(18):3718-24. 
34.Katano A, Takahashi W, Yamashita H, Yamamoto K, Ando M, Yoshida M, et al. Radiotherapy alone and with concurrent chemotherapy for nasopharyngeal carcinoma: A retrospective study. Medicine. 2018;97(18):e0502.

35.Clavel S, Nguyen DH, Fortin B, Despres P, Khaouam N, Donath D, et al. Simultaneous integrated boost using intensity-modulated radiotherapy compared with conventional radiotherapy in patients treated with concurrent carboplatin and 5-fluorouracil for locally advanced oropharyngeal carcinoma. International journal of radiation oncology, biology, physics. 2012;82(2):582-9.

36.Yan H, Cao X, Wang J. Application of intensity-modulated radiation therapy in the treatment of nasopharyngeal carcinoma. Oncology letters. 2017;14(6):7773-6.

37.Chen NB, Qiu B, Zhang J, Qiang MY, Zhu YJ, Wang B, et al. Intensity-Modulated Radiotherapy versus ThreeDimensional Conformal Radiotherapy in Definitive Chemoradiotherapy for Cervical Esophageal Squamous Cell Carcinoma: Comparison of Survival Outcomes and Toxicities. Cancer research and treatment: official journal of Korean Cancer Association. 2020;52(1):31-40.

38.Korpics MC, Turchan WT, Rooney MK, Koshy M, Spiotto MT. Patterns of Care and Outcomes of IntensityModulated Radiotherapy and 3D Conformal Radiotherapy for Early Stage Glottic Cancer: A National Cancer Database Analysis. Cancers (Basel). 2019;11(12).

39.You R, Cao YS, Huang PY, Chen L, Yang Q, Liu YP, et al. The Changing Therapeutic Role of Chemoradiotherapy for Loco-regionally Advanced Nasopharyngeal Carcinoma from Two/Three-Dimensional Radiotherapy to Intensity-Modulated Radiotherapy: A Network Meta-Analysis. Theranostics. 2017;7(19):482535.

\section{Tables}




\begin{tabular}{|c|c|c|c|c|}
\hline \multirow[t]{2}{*}{ Characteristics } & All $(n=224)$ & IMRT $(n=108)$ & 3D-CRT (n=116) & \multirow[t]{2}{*}{$P$ value } \\
\hline & $\mathrm{N}(\%)$ & $\mathrm{N}(\%)$ & $\mathrm{N}(\%)$ & \\
\hline \multicolumn{5}{|l|}{ Gender } \\
\hline Male & 176 (78.57) & $80(74.07)$ & 96 (82.76) & 0.1135 \\
\hline Female & $48(21.43)$ & $28(25.93)$ & $20(17.24)$ & \\
\hline Age (years) & $50.17(11.41)$ & 49.05 (11.52) & $51.22(11.26)$ & 0.1556 \\
\hline$\leq 60$ & $182(81.25)$ & $89(82.41)$ & $93(80.17)$ & 0.6685 \\
\hline$>60$ & 42 (18.75) & 19 (17.59) & $23(19.83)$ & \\
\hline Current smoker & $50(22.32)$ & $22(20.37)$ & $28(24.14)$ & 0.4986 \\
\hline Current drinker & $41(18.30)$ & $16(14.81)$ & 25 (21.55) & 0.1926 \\
\hline BMI & $22.92(3.17)$ & $22.98(3.11)$ & $22.86(3.26)$ & 0.7987 \\
\hline Comorbidity & $59(26.34)$ & $27(25.00)$ & 32 (27.59) & 0.6606 \\
\hline Hypertension & 25 (11.16) & $10(9.26)$ & 15 (12.93) & 0.3832 \\
\hline Diabetes & $10(4.46)$ & $5(4.63)$ & $5(4.31)$ & 0.9080 \\
\hline Hepatitis & $26(11.61)$ & $13(12.04)$ & $13(11.21)$ & 0.8463 \\
\hline Tuberculosis & $3(1.34)$ & $1(0.93)$ & $2(1.72)$ & 0.6035 \\
\hline \multicolumn{5}{|l|}{ TNM stage } \\
\hline प & $8(3.57)$ & $4(3.70)$ & $4(3.45)$ & 0.9907 \\
\hline प & 32 (14.29) & 15 (13.89) & $17(14.66)$ & \\
\hline प & 85 (37.95) & $42(38.89)$ & $43(37.07)$ & \\
\hline प & $95(42.41)$ & $45(41.67)$ & $50(43.10)$ & \\
\hline Total radiation dosage (Gy) & $68.68(6.99)$ & $69.57(1.97)$ & $67.95(9.23)$ & 0.1149 \\
\hline Radiation fraction & $2.09(0.11)$ & $2.19(0.04)$ & $2.02(0.09)$ & $<0.0001$ \\
\hline Length of RT to CC (days) & $7.43(9.22)$ & $7.44(9.5)$ & $7.43(9.01)$ & 0.9889 \\
\hline Length of IC to RT (days) & $50.23(30.37)$ & $52.69(33.42)$ & $48(27.31)$ & 0.3030 \\
\hline \multicolumn{5}{|l|}{ IC taxane-based drugs } \\
\hline Taxol & $101(45.09)$ & $46(42.59)$ & $55(47.41)$ & 0.0281 \\
\hline Docetaxel & $53(23.66)$ & $34(31.48)$ & $19(16.38)$ & \\
\hline \multicolumn{5}{|l|}{ IC platinum-based drugs } \\
\hline Cisplatin & $153(68.30)$ & $66(61.11)$ & $87(75.00)$ & 0.0023 \\
\hline
\end{tabular}




\begin{tabular}{|lllll|}
\hline Nedaplatin & $25(11.16)$ & $19(17.59)$ & $6(5.17)$ & \\
\hline IC 5-FU treated & $19(8.48)$ & $12(11.11)$ & $7(6.03)$ & 0.1730 \\
\hline CC platinum-based drugs & & & & \\
\hline Cisplatin & $112(50.00)$ & $47(43.52)$ & $65(56.03)$ & $<0.0001$ \\
\hline Nedaplatin & $48(21.43)$ & $38(35.19)$ & $10(8.62)$ & \\
\hline Short-term effects & & & & \\
CR & $19(8.48)$ & $11(10.19)$ & $8(6.90)$ & 0.0007 \\
\hline PR & $95(42.41)$ & $60(55.56)$ & $35(30.17)$ & \\
\hline
\end{tabular}

Abbreviations: IMRT intensity modulated radiation therapy, $3 D-C R T$ three-dimensional conventional radiotherapy, $R T$ radiotherapy, IC induction chemotherapy, 5-FU 5-fluorouracil, $C C$ concurrent chemotherapy, $C R$ complete remission, $P R$ complete remission 


\begin{tabular}{|c|c|c|c|c|}
\hline \multirow[t]{2}{*}{ Variables } & All $(n=224)$ & IMRT (n=108) & 3D-CRT $(n=116)$ & \multirow[t]{2}{*}{$P$ value } \\
\hline & $\mathrm{N}(\%)$ & $\mathrm{N}(\%)$ & $\mathrm{N}(\%)$ & \\
\hline Radiation-induced injury & 219 (97.77) & $107(99.07)$ & $112(96.55)$ & 0.2016 \\
\hline Dermatitis & $199(88.84)$ & $97(89.81)$ & $102(87.93)$ & 0.6546 \\
\hline Flush & $69(30.80)$ & $39(36.11)$ & $30(25.86)$ & 0.0969 \\
\hline Hyperpigmentation & $137(61.16)$ & $57(52.78)$ & $80(68.97)$ & 0.0130 \\
\hline Dry desquamation & $83(37.05)$ & $39(36.11)$ & $44(37.93)$ & 0.7781 \\
\hline Moist desquamation & $27(12.05)$ & $23(21.30)$ & $4(3.45)$ & $<0.0001$ \\
\hline Erythema & $14(6.25)$ & $14(12.96)$ & $0(0)$ & $<0.0001$ \\
\hline Moderate edema & $9(4.02)$ & $8(7.41)$ & $1(0.86)$ & 0.0127 \\
\hline Ulceration & $76(33.93)$ & $35(32.41)$ & $41(35.34)$ & 0.6427 \\
\hline Exudate & $48(21.43)$ & $27(25.00)$ & $21(18.10)$ & 0.2088 \\
\hline Infection & $8(3.57)$ & $5(4.63)$ & $3(2.59)$ & 0.4102 \\
\hline Pain & $40(17.86)$ & $25(23.15)$ & $15(12.93)$ & 0.0460 \\
\hline Pruritus & $29(12.95)$ & $22(20.37)$ & $7(6.03)$ & 0.0014 \\
\hline Oral mucositis & $216(96.43)$ & $104(96.3)$ & $112(96.55)$ & 0.9180 \\
\hline Hyperaemia & $115(51.34)$ & $51(47.22)$ & $64(55.17)$ & 0.2342 \\
\hline Ulceration & $153(68.3)$ & $70(64.81)$ & $83(71.55)$ & 0.2789 \\
\hline Edema & $14(6.25)$ & $6(5.56)$ & $8(6.90)$ & 0.6787 \\
\hline Flush & $57(25.45)$ & $27(25.00)$ & $30(25.86)$ & 0.8823 \\
\hline Leukasmus & $85(37.95)$ & $41(37.96)$ & $44(37.93)$ & 0.9961 \\
\hline Xerostomia & $88(39.29)$ & $55(50.93)$ & $33(28.45)$ & 0.0006 \\
\hline Bone marrow toxicity & $88(39.29)$ & $28(25.93)$ & $60(51.72)$ & $<0.0001$ \\
\hline Gastrointestinal injury & $45(20.09)$ & $32(29.63)$ & $13(11.21)$ & 0.0006 \\
\hline Nausea and vomiting & $85(37.95)$ & $42(38.89)$ & $43(37.07)$ & 0.7791 \\
\hline Anemia & $30(13.39)$ & $11(10.19)$ & $19(16.38)$ & 0.1738 \\
\hline Leukopenia & $85(37.95)$ & $47(43.52)$ & $38(32.76)$ & 0.0973 \\
\hline Pneumonitis & $7(3.13)$ & $5(4.63)$ & $2(1.72)$ & 0.2117 \\
\hline Encephalopathy & $7(3.13)$ & $2(1.85)$ & $5(4.31)$ & 0.2906 \\
\hline Otitis media & $10(4.46)$ & $1(0.93)$ & $9(7.76)$ & 0.0134 \\
\hline
\end{tabular}




\begin{tabular}{|lllll|}
\hline Widespread injury & & & \\
\hline Headache & $16(7.14)$ & $7(6.48)$ & $9(7.76)$ & 0.7107 \\
\hline Pain & $63(28.13)$ & $8(7.41)$ & $55(47.41)$ & $<0.0001$ \\
\hline Poor spirit & $45(20.09)$ & $21(19.44)$ & $24(20.69)$ & 0.8162 \\
\hline Poor sleep & $47(20.98)$ & $19(17.59)$ & $28(24.14)$ & 0.2293 \\
\hline Poor appetite & $168(75.00)$ & $76(70.37)$ & $92(79.31)$ & 0.1226 \\
\hline Lose weight & $87(38.84)$ & $47(43.52)$ & $40(34.48)$ & 0.1656 \\
\hline Gastrointestinal dysfunction & $26(11.61)$ & $7(6.48)$ & $19(16.38)$ & 0.0208 \\
\hline
\end{tabular}

Abbreviations: IMRT intensity modulated radiation therapy, $3 D-C R T$ three-dimensional conventional radiotherapy

\begin{tabular}{|c|c|c|c|c|c|c|c|c|c|c|}
\hline \multirow[t]{2}{*}{ Variables } & \multicolumn{4}{|l|}{ IMRT } & \multicolumn{4}{|c|}{ 3D-CRT } & \multicolumn{2}{|l|}{ Log-rank } \\
\hline & $\begin{array}{l}\text { M } \\
\text { (days) }\end{array}$ & SD & $\begin{array}{l}M \\
(\%)\end{array}$ & SD & $\begin{array}{l}\text { M } \\
\text { (days) }\end{array}$ & SD & $\begin{array}{l}\text { Median } \\
(\%)\end{array}$ & SD & $\begin{array}{l}\text { Chi- } \\
\text { Square }\end{array}$ & $\begin{array}{l}P \\
\text { value }\end{array}$ \\
\hline $\begin{array}{l}\text { Radiation- } \\
\text { induced injury }\end{array}$ & 11 & 1 & 48.15 & 4.81 & 13 & 1 & 40.50 & 4.61 & 2.0251 & 0.1547 \\
\hline Dermatitis & 27 & 1 & 32.41 & 4.50 & 32 & 1 & 23.19 & 3.99 & 2.8826 & 0.0895 \\
\hline Oral mucositis & 15 & 1 & 30.56 & 4.43 & 17 & 1 & 22.03 & 3.89 & 1.6436 & 0.1998 \\
\hline $\begin{array}{l}\text { Bone marrow } \\
\text { toxicity }\end{array}$ & 59 & 3 & 26.61 & 4.73 & 52 & 4 & 48.00 & 4.90 & 8.8966 & 0.0029 \\
\hline $\begin{array}{l}\text { Gastrointestinal } \\
\text { injury }\end{array}$ & 34 & 2 & 27.78 & 4.31 & 29 & 1 & 9.93 & 2.84 & 10.7118 & 0.0011 \\
\hline $\begin{array}{l}\text { Nausea and } \\
\text { vomiting }\end{array}$ & 39 & 2 & 31.48 & 4.47 & 38 & 2 & 27.18 & 4.24 & 0.2118 & 0.6453 \\
\hline Anemia & 45 & 1 & 7.43 & 2.53 & 69 & 2 & 12.76 & 3.19 & 1.1112 & 0.2918 \\
\hline Leukopenia & 63 & 5 & 59.63 & 12.38 & 67 & 3 & 50.17 & 8.33 & 5.7515 & 0.0165 \\
\hline
\end{tabular}

Abbreviations: $M$ median, $S D$ standard error, $I M R T$ intensity modulated radiation therapy, $3 D-C R T$ threedimensional conventional radiotherapy 
Table 4 Prediction of radiation-induced acute injuries in Cox proportional hazards analysis

\begin{tabular}{|c|c|c|c|c|c|c|c|c|}
\hline \multirow[t]{2}{*}{ Characteristics } & \multicolumn{2}{|c|}{$\begin{array}{l}\text { Bone marrow } \\
\text { toxicity }\end{array}$} & \multicolumn{2}{|c|}{$\begin{array}{l}\text { Gastrointestinal } \\
\text { injury }\end{array}$} & \multicolumn{2}{|c|}{ Leukopenia } & \multicolumn{2}{|c|}{ Oral mucositis } \\
\hline & $\begin{array}{l}\mathrm{HR}(95 \% \\
\mathrm{Cl})\end{array}$ & $\begin{array}{l}P \\
\text { value }\end{array}$ & $\begin{array}{l}\mathrm{HR}(95 \% \\
\mathrm{Cl})\end{array}$ & $\begin{array}{l}P \\
\text { value }\end{array}$ & $\begin{array}{l}\mathrm{HR}(95 \% \\
\mathrm{Cl})\end{array}$ & $\begin{array}{l}P \\
\text { value }\end{array}$ & $\begin{array}{l}\mathrm{HR} \\
(95 \% \\
\mathrm{Cl})\end{array}$ & $P$ value \\
\hline $\begin{array}{l}\text { IMRT vs. 3D- } \\
\text { CRT }\end{array}$ & $\begin{array}{l}2.557 \\
(1.370- \\
4.775)\end{array}$ & 0.0032 & $\begin{array}{l}0.432 \\
(0.210- \\
0.890)\end{array}$ & 0.0228 & $\begin{array}{l}0.492 \\
(0.277- \\
0.872)\end{array}$ & 0.0151 & $\begin{array}{l}0.681 \\
(0.138- \\
3.358)\end{array}$ & 0.6365 \\
\hline $\begin{array}{l}\text { Gender (male } \\
\text { vs. female) }\end{array}$ & $\begin{array}{l}2.640 \\
(1.349- \\
5.164)\end{array}$ & 0.0046 & $\begin{array}{l}1.727 \\
(0.809- \\
3.685)\end{array}$ & 0.1576 & $\begin{array}{l}0.997 \\
(0.501- \\
1.983)\end{array}$ & 0.9930 & $\begin{array}{l}1.727 \\
(0.922- \\
3.235)\end{array}$ & 0.0881 \\
\hline $\begin{array}{l}\text { Age }(\leq 60 \text { vs. } \\
>60 \text { years) }\end{array}$ & $\begin{array}{l}1.844 \\
(0.921- \\
3.690)\end{array}$ & 0.0840 & $\begin{array}{l}0.733 \\
(0.272- \\
1.977)\end{array}$ & 0.5399 & $\begin{array}{l}1.359 \\
(0.704- \\
2.624)\end{array}$ & 0.3605 & $\begin{array}{l}2.593 \\
(1.227- \\
5.480)\end{array}$ & 0.0126 \\
\hline $\begin{array}{l}\text { Current } \\
\text { smoker }\end{array}$ & $\begin{array}{l}1.496 \\
(0.740- \\
3.023)\end{array}$ & 0.2616 & $\begin{array}{l}0.646 \\
(0.227- \\
1.834)\end{array}$ & 0.4115 & $\begin{array}{l}0.705 \\
(0.340- \\
1.463)\end{array}$ & 0.3476 & $\begin{array}{l}1.530 \\
(0.741- \\
3.159)\end{array}$ & 0.2500 \\
\hline Current drinker & $\begin{array}{l}1.051 \\
(0.517- \\
2.134)\end{array}$ & 0.8914 & $\begin{array}{l}0.802 \\
(0.268- \\
2.399)\end{array}$ & 0.6925 & $\begin{array}{l}1.048 \\
(0.492- \\
2.234)\end{array}$ & 0.9031 & $\begin{array}{l}0.628 \\
(0.285- \\
1.382)\end{array}$ & 0.2475 \\
\hline BMI & $\begin{array}{l}1.085 \\
(0.731- \\
1.608)\end{array}$ & 0.6866 & $\begin{array}{l}1.902 \\
(1.149- \\
3.149)\end{array}$ & 0.0124 & $\begin{array}{l}0.758 \\
(0.504- \\
1.138)\end{array}$ & 0.1817 & $\begin{array}{l}1.419 \\
(0.940- \\
2.142)\end{array}$ & 0.0960 \\
\hline
\end{tabular}

Comorbidity

\begin{tabular}{|c|c|c|c|c|c|c|c|c|}
\hline Hypertension & $\begin{array}{l}0.960 \\
(0.363- \\
2.538)\end{array}$ & 0.9341 & $\begin{array}{l}0.751 \\
(0.215- \\
2.627)\end{array}$ & 0.6536 & $\begin{array}{l}0.121 \\
(0.016- \\
0.922)\end{array}$ & 0.0415 & $\begin{array}{l}0.711 \\
(0.308- \\
1.641)\end{array}$ & 0.4247 \\
\hline Diabetes & - & 0.2827 & - & 0.9877 & $\begin{array}{l}1.955 \\
(0.496- \\
7.706)\end{array}$ & 0.3382 & $\begin{array}{l}0.524 \\
(0.084- \\
3.256)\end{array}$ & 0.4880 \\
\hline Hepatitis & $\begin{array}{l}3.629 \\
(1.851- \\
7.113)\end{array}$ & 0.0002 & $\begin{array}{l}1.151 \\
(0.458- \\
2.889)\end{array}$ & 0.7648 & $\begin{array}{l}1.886 \\
(1.001- \\
3.555)\end{array}$ & 0.0496 & $\begin{array}{l}2.474 \\
(1.187- \\
5.156)\end{array}$ & 0.0156 \\
\hline Tuberculosis & - & 0.9932 & - & 0.9930 & $\begin{array}{l}1.359 \\
(0.126- \\
14.616)\end{array}$ & 0.8002 & $\begin{array}{l}0.167 \\
(0.021- \\
1.343)\end{array}$ & 0.0924 \\
\hline T category & $\begin{array}{l}0.926 \\
(0.652- \\
1.317)\end{array}$ & 0.6703 & $\begin{array}{l}1.247 \\
(0.749- \\
2.076)\end{array}$ & 0.3952 & $\begin{array}{l}1.016 \\
(0.701- \\
1.471)\end{array}$ & 0.9343 & $\begin{array}{l}1.258 \\
(0.909- \\
1.741)\end{array}$ & 0.1669 \\
\hline $\mathrm{N}$ category & $\begin{array}{l}0.900 \\
(0.587- \\
1.379)\end{array}$ & 0.6289 & $\begin{array}{l}0.950 \\
(0.599- \\
1.506)\end{array}$ & 0.8263 & $\begin{array}{l}0.832 \\
(0.566- \\
1.224)\end{array}$ & 0.3507 & $\begin{array}{l}0.990 \\
(0.709- \\
1.381)\end{array}$ & 0.9515 \\
\hline M category & $\begin{array}{l}0.674 \\
(0.210- \\
2.166)\end{array}$ & 0.5083 & $\begin{array}{l}0.640 \\
(0.173- \\
2.364)\end{array}$ & 0.5027 & $\begin{array}{l}1.701 \\
(0.634- \\
4.565)\end{array}$ & 0.2918 & $\begin{array}{l}0.382 \\
(0.150- \\
0.974)\end{array}$ & 0.0439 \\
\hline
\end{tabular}




\begin{tabular}{|c|c|c|c|c|c|c|c|c|}
\hline TNM stage & $\begin{array}{l}1.456 \\
(0.827- \\
2.566)\end{array}$ & 0.1931 & $\begin{array}{l}0.900 \\
(0.437- \\
1.853)\end{array}$ & 0.7742 & $\begin{array}{l}1.128 \\
(0.640- \\
1.988)\end{array}$ & 0.6771 & $\begin{array}{l}0.716 \\
(0.452- \\
1.134)\end{array}$ & 0.1544 \\
\hline $\begin{array}{l}\text { Radiation } \\
\text { fraction }\end{array}$ & $\begin{array}{l}0.382 \\
(0.066- \\
2.207)\end{array}$ & 0.2823 & $\begin{array}{l}1.33 \\
(0.132- \\
13.409)\end{array}$ & 0.8091 & $\begin{array}{l}1.402 \\
(0.090- \\
21.875)\end{array}$ & 0.8097 & $\begin{array}{l}0.526 \\
(0.113- \\
2.445)\end{array}$ & 0.4123 \\
\hline $\begin{array}{l}\text { IC taxane- } \\
\text { based drugs }\end{array}$ & $\begin{array}{l}1.152 \\
(0.484- \\
2.742)\end{array}$ & 0.7496 & $\begin{array}{l}2.954 \\
(1.172- \\
7.447)\end{array}$ & 0.0217 & $\begin{array}{l}2.174 \\
(0.976- \\
4.840)\end{array}$ & 0.0573 & $\begin{array}{l}1.480 \\
(0.849- \\
2.580)\end{array}$ & 0.1668 \\
\hline $\begin{array}{l}\text { IC platinum- } \\
\text { based drugs }\end{array}$ & $\begin{array}{l}0.475 \\
(0.082- \\
2.750)\end{array}$ & 0.4056 & $\begin{array}{l}0.547 \\
(0.135- \\
2.221)\end{array}$ & 0.3987 & $\begin{array}{l}0.861 \\
(0.256- \\
2.890)\end{array}$ & 0.8081 & $\begin{array}{l}1.733 \\
(0.680- \\
4.419)\end{array}$ & 0.2493 \\
\hline IC 5-FU treated & $\begin{array}{l}0.533 \\
(0.120- \\
2.358)\end{array}$ & 0.4065 & $\begin{array}{l}5.632 \\
(1.422- \\
22.302)\end{array}$ & 0.0138 & $\begin{array}{l}1.024 \\
(0.326- \\
3.213)\end{array}$ & 0.9674 & $\begin{array}{l}7.215 \\
(3.073- \\
16.939)\end{array}$ & $<0.0001$ \\
\hline $\begin{array}{l}\text { CC platinum- } \\
\text { based drugs }\end{array}$ & $\begin{array}{l}0.859 \\
(0.567- \\
1.301)\end{array}$ & 0.4725 & $\begin{array}{l}2.362 \\
(1.099- \\
5.076)\end{array}$ & 0.0276 & $\begin{array}{l}1.192 \\
(0.648- \\
2.195)\end{array}$ & 0.5719 & $\begin{array}{l}0.752 \\
(0.504- \\
1.122)\end{array}$ & 0.1628 \\
\hline $\begin{array}{l}\text { Short-term } \\
\text { effects }\end{array}$ & $\begin{array}{l}0.844 \\
(0.576- \\
1.238)\end{array}$ & 0.3856 & $\begin{array}{l}1.243 \\
(0.778- \\
1.987)\end{array}$ & 0.3627 & $\begin{array}{l}0.977 \\
(0.597- \\
1.598)\end{array}$ & 0.9256 & $\begin{array}{l}1.083 \\
(0.758- \\
1.547)\end{array}$ & 0.6631 \\
\hline
\end{tabular}

Abbreviations: IMRT intensity modulated radiation therapy, 3D-CRT three-dimensional conventional radiotherapy, $H R$ hazard ratio, $C /$ confidence interval, $I C$ induction chemotherapy, 5- $F U 5$-fluorouracil, $C C$ concurrent chemotherapy

\section{Figures}




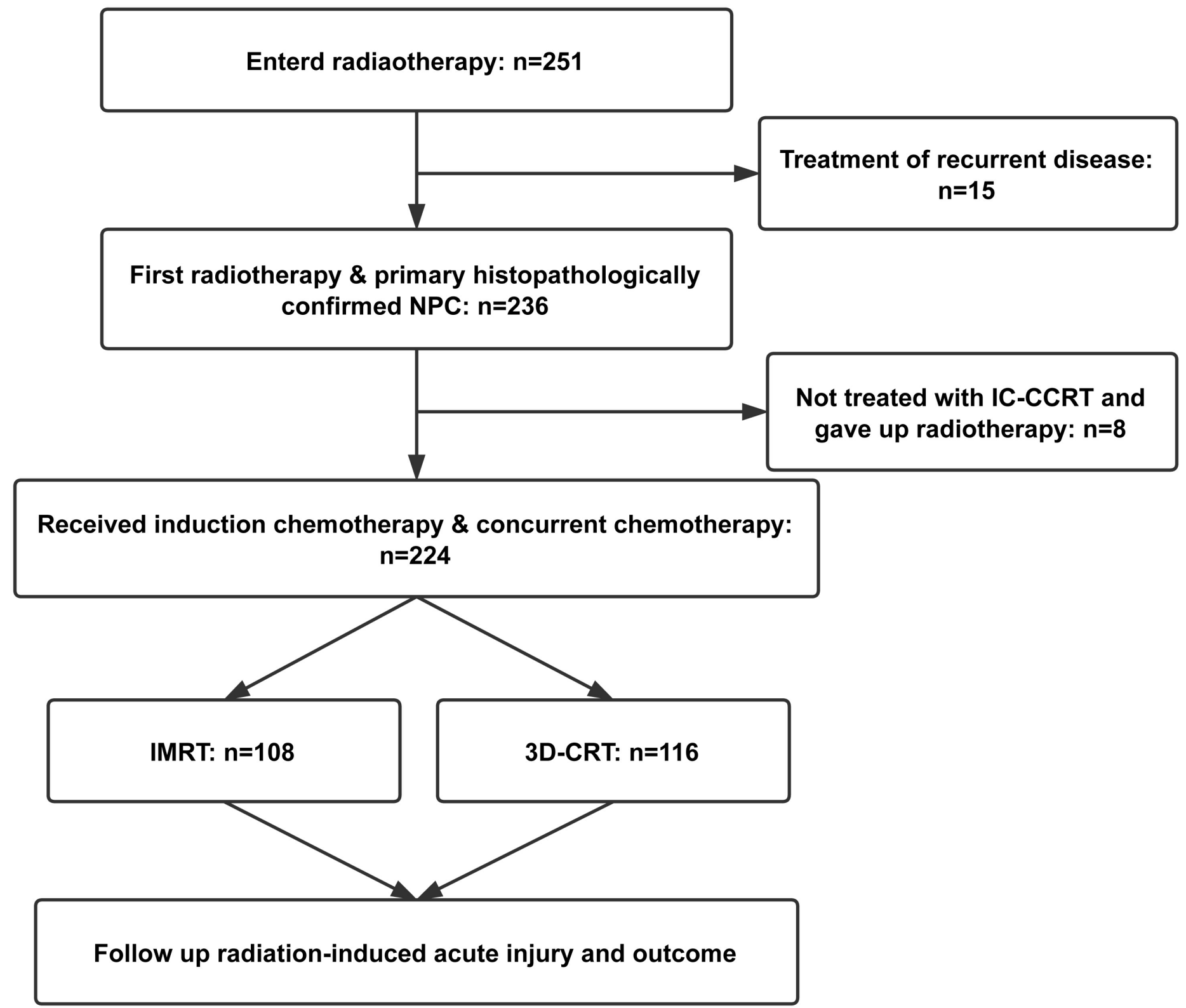

Figure 1

The consolidated standards of reporting trials (CONSORT) flow-chart for the study. Abbreviation: IMRT intensity modulated radiation therapy, 3D-CRT three-dimensional conventional radiotherapy, NPC nasopharyngeal carcinoma, IC-CCRT induction chemotherapy followed by concurrent chemoradiotherapy 

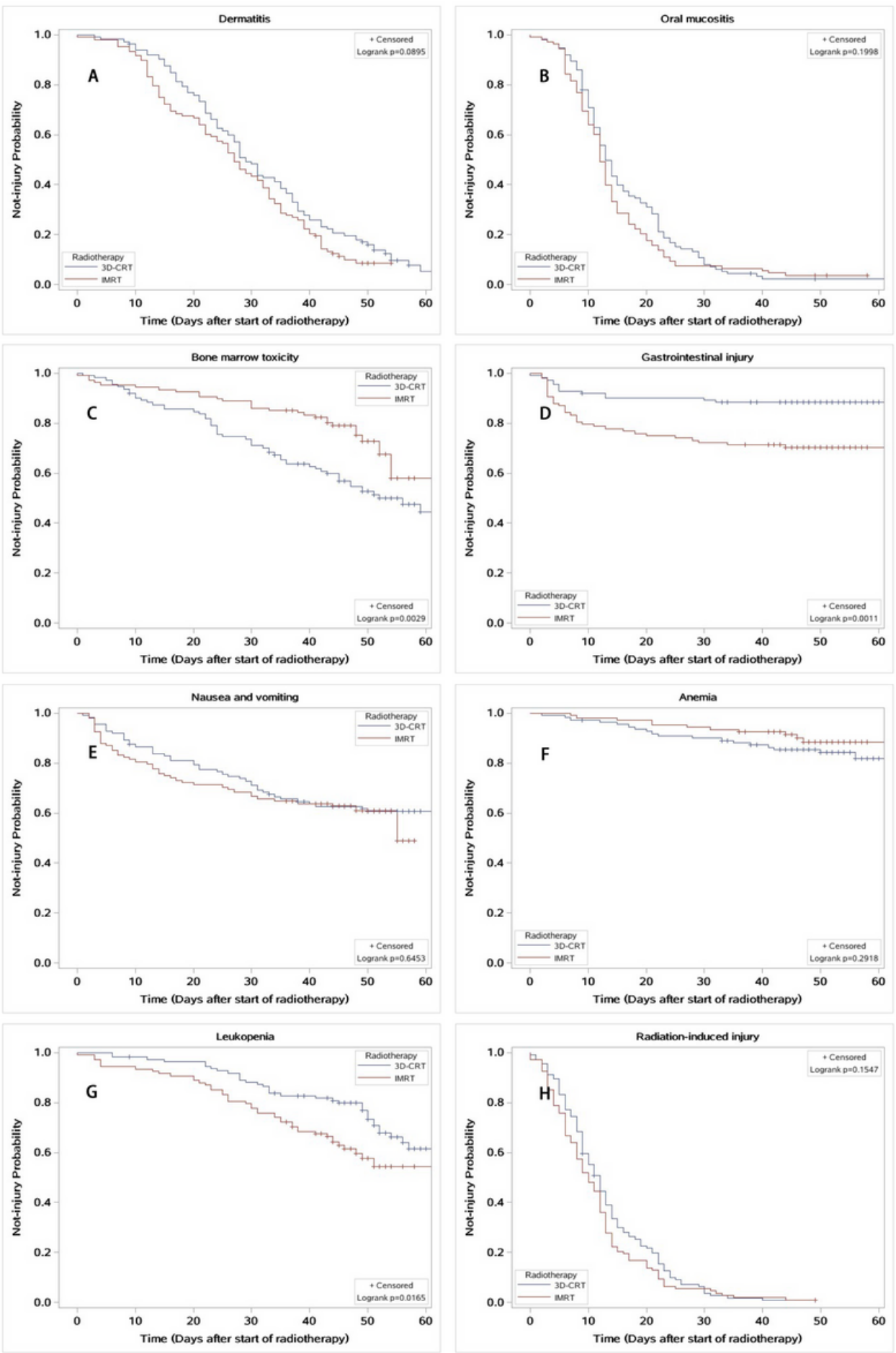

\section{Figure 2}

Kaplan-Meier curves for dermatitis (A), oral mucositis (B), bone marrow toxicity (C), gastrointestinal injury (D), nausea and vomiting $(E)$, anemia $(F)$, leukopenia $(G)$, radiation-induced injury $(H)$ in NPC patients treated with IMRT vs. 3D-CRT. Abbreviation: IMRT intensity modulated radiation therapy, 3D-CRT three-dimensional conventional radiotherapy 

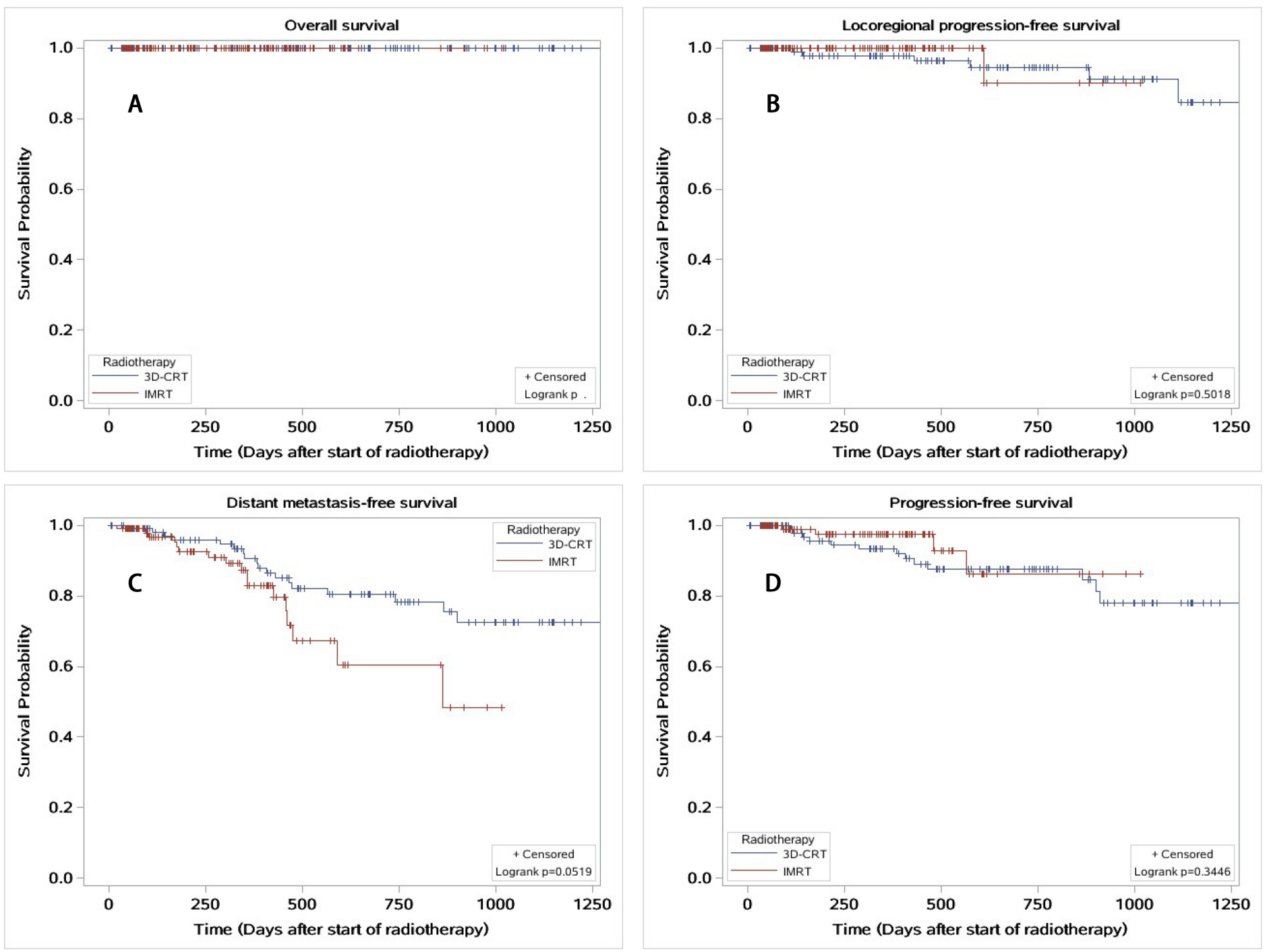

\section{Figure 3}

The survival curves of overall survival (OS) (A), locoregional progression-free survival (LRFS) (B), distant metastasis-free survival (DMFS) (C) and progression-free survival (PFS) (D) for NPC patients received IMRT vs. 3D-CRT. Abbreviation: IMRT intensity modulated radiation therapy, 3D-CRT three-dimensional conventional radiotherapy 